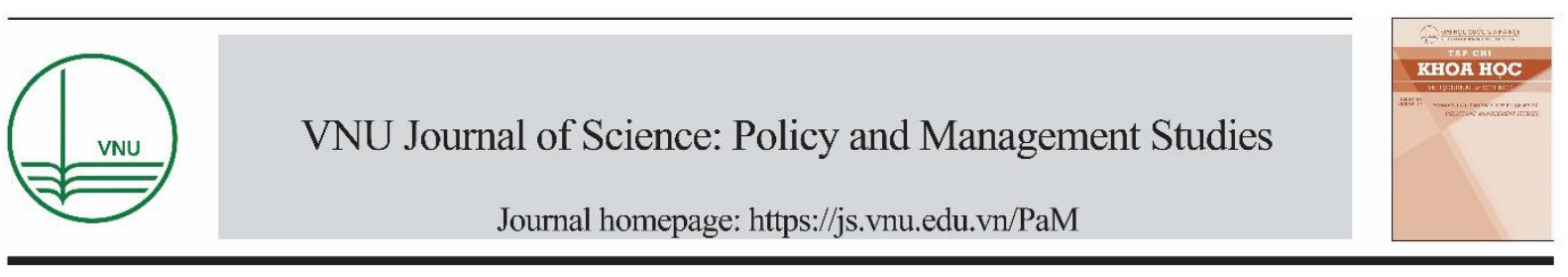

\title{
Review Article \\ Population Policy and Fertility Change in Vietnam in the Period from now to 2030
}

\author{
Ha Viet Hung ${ }^{1, *}$, Tran Thi Minh Ngoc ${ }^{2}$ \\ ${ }^{1}$ Institute for Sociology and Development, Ho Chi Minh National Political Academy, \\ 135 Nguyen Phong Sac, Cau Giay, Hanoi, Vietnam \\ ${ }^{2}$ Academy of Politics Region I, 15 Khuat Duy Tien, Thanh Xuan, Hanoi, Vietnam
}

Received 24 August 2020

Revised 03 November 2020; Accepted 05 November 2020

\begin{abstract}
It is known that Vietnam has started an aging period that accompanied with the challenge of labor shortage for economic development. The way of fertility change in the modern society is that the more the socio-economic development the lower the level of fertility. The practice of fertility change in developed countries indicates that it has been very difficult to enhance the level of fertility once it was rather lower than the replacement one. The potential of increasing for an economy would depend much on the percentage of increasing labor force. Under the market economy, the labor force is floating from areas to areas by the way of demand-supply. People are moving from regions with excess of labors to regions with shortage of labor. For the whole country, the labor force would move from 33 provinces/cities of the higher fertility to those 21 provinces/cities of the lower fertility, therefore keeping the fertility at replacement level for the whole country. It is not rational to set up a target of decreasing fertility by $10 \%$ for 33 provinces/cities of the higher fertility because it would not keep the general fertility at replacement level in the period from now up to 2030.
\end{abstract}

Keywords: Population transition, population policy, total fertility rate.

\footnotetext{
${ }^{*}$ Corresponding author.

Email address: hunghv135@gmail.com
}

https://doi.org/10.25073/2588-1116/vnupam.4259 


\title{
Chính sách dân số từ góc nhìn biến đổi mức sinh ở Việt Nam giai đoạn từ nay đến 2030
}

\author{
Hà Việt Hùng ${ }^{1, *}$, Trần Thị Minh Ngọc ${ }^{2}$ \\ ${ }^{1}$ Viện Xã hội học và Phát triển, Học viện Chính trị Quốc gia Hồ Chí Minh, \\ 135 Nguyễn Phong Sắc, Cầu Giấy, Hà Nội, Việt Nam \\ ${ }^{2}$ Học viện Chính trị Khu vưc I, 15 Khuất Duy Tiến, Thanh Xuân, Hà Nội, Việt Nam \\ Nhận ngày 24 tháng 8 năm 2020 \\ Chỉnh sửa ngày 03 tháng 11 năm 2020; Chấp nhận đăng ngày 05 tháng 11 năm 2020
}

\begin{abstract}
Tóm tắt: Việt Nam đã đi vào quá trình già hóa dân số cùng với thách thức về thiếu nguồn nhân lực cho phát triển kinh tế-xã hội. Quy luật biến đổi mức sinh trong xã hội hiện đại là kinh tế xã hội càng phát triển thì mức sinh càng xuống thấp. Thực tiễn các quốc gia phát triển cho thấy, khi mức sinh thấp dưới mức sinh thay thế thì rất khó để làm tăng mức sinh lên. Tiềm năng tăng trưởng của một nền kinh tế phụ thuộc nhiều vào tỷ lệ tăng trưởng nguồn nhân lực. Trong kinh tế thị trường, nguồn nhân lực sẽ từ các địa phương có nhiều lao động dịch chuyển tới các địa phương cần lao động. Trên phạm vi toàn quốc, nguồn nhân lực ở 33 tỉnh, thành phố có mức sinh cao hơn sẽ có thể giúp cân đối với nguồn nhân lực ở 21 tỉnh, thành phố có mức sinh thấp hơn. Việc đặt ra mục tiêu giảm $10 \%$ tổng tỷ suất sinh của 33 tỉnh, thành phố là không phù hợp đối với việc thực hiện mục tiêu chung của chính sách dân số là duy trì vững chắc mức sinh thay thế trong giai đoạn từ nay đến 2030.
\end{abstract}

Tù khóa: Quá độ dân số, Chính sách dân số, Tổng tỷ suất sinh.

\section{Mở đầu}

Trong 30 năm vừa qua, mức sinh giảm nhanh là một đặc điểm nổi bật trong biến động dân số ở nước ta. Khi mức tử vong của dân số dao động ở mức thấp và tương đối ổn định, thì mức sinh là một yếu tố quan trọng nhất có tác động tới quy mô dân số. Số con trung bình của phụ nữ (TFR) Việt Nam đã giảm từ 3,8 con, năm 1989 [1], xuống còn 2,1 con (mức sinh thay thế) vào năm 2005-2006. Mức sinh thay thế này đã được duy trì tương đối ổn định trong vòng 15 năm vừa qua. Đây là kết quả của việc thực hiện thắng lợi chính sách dân số-kế hoạch hóa gia đình của chính phủ Việt Nam. Nghị quyết Trung ương 4 năm 1993 đã đề ra mục tiêu về đạt mức sinh thay thế vào năm 2015, nhưng Việt Nam đã hoàn thành mục tiêu này sớm trước 10 năm [2]. Mục tiêu và giải pháp của chinh sách dân số theo vùng trong giai đoạn hiện nay có tính khả thi và phù hợp như thế nào đối với việc đảm bảo duy trì mức sinh thay thế trên phạm vi cả nước là chủ đề bàn luận của bài viết nghiên cứu này.

\section{Biến đổi mức sinh của dân số}

Mức sinh là số trẻ em sinh ra sống. Để đo lường mức sinh biến đổi thế nào theo thời gian, các nhà khoa học thường sử dụng chỉ báo Tổng tỷ suất sinh (viết tắt tiếng Anh là TFR). Tổng tỷ suất sinh được hiểu là số con sinh ra sống bình quân của một người phụ nữ trong suốt cả cuộc đời, nếu người phụ nữ đó trong suốt thời kỳ sinh

\footnotetext{
*Tác giả liên hệ.

Địa chỉ email: hunghv135@gmail.com

https://doi.org/10.25073/2588-1116/vnupam.4259
} 
đẻ tuân theo tỷ suất sinh đặc trưng theo tuổi như quan sát được trong 12 tháng trước điều tra. Mức sinh thay thế là mức sinh mà một đoàn hệ phụ nữ trung bình có vừa đủ con gái để "thay thế" họ trong quá trình tái sinh sản dân số; tương ứng với Tổng tỷ suất sinh (TFR) là 2,10 con/phụ nữ [5].

Trước khi các xã hội nông nghiệp truyền thống chuyển mình bước vào quá trình công nghiệp hóa, cả mức tử vong và mức sinh tự nhiên đều cao và ổn định. Nhằm duy trì phát triển dân số, các cộng đồng dân cư có mức sinh tự nhiên đều ở mức cao nhằm bù lại cho mức tử vong cao. Một lý do nữa của mức sinh cao là khi đó chưa có các biện pháp tránh thai hiện đại có hiệu quả. Trong xã hội nông nghiệp truyền thống, về cơ bản, hành vi sinh đẻ của con người là hành vi sinh học tự nhiên như "Trời sinh voi, trời sinh cỏ".

Khi các xã hội đi vào thời kỳ công nghiệp hóa, những biến động cơ bản về mức tử vong và mức sinh của dân số bắt đầu diễn ra. Các nhà khoa học gọi đây là giai đoạn đầu của thời kỳ quá độ dân số. Cách mạng công nghiệp làm cho năng suất lao động tăng lên mạnh mẽ, bao gồm cả trong sản xuất nông nghiệp. nạn đói hầu như biến mất ở các xã hội tiền công nghiệp khi đi vào công nghiệp hóa. Y học cũng bắt đầu phát triển mạnh cùng với cuộc cách mạng khoa học-kỹ thuật, các loại văcxin được phát minh, sản xuất hàng loạt và sử dụng rộng rãi. Hai yếu tố làm cho mức tử vong cao ở các xã hội nông nghiệp truyền thống là nạn đói và dịch bệnh không còn ảnh hưởng đáng kể trong các xã hội công nghiệp hóa [3].

Ở giai đoạn đầu của thời kỳ quá độ dân số, mức tử vong của dân số đã giảm đi mạnh mẽ. Trong giai đoạn đầu này, khi mức sinh chưa giảm và mức tử vong lại giảm mạnh đã làm cho quy mô dân số tăng lên đột ngột. Các nhà khoa học gọi giai đoạn này ở châu Âu là bùng nổ dân số lần thứ nhất.

Trong các xã hội nông nghiệp truyền thống, các cặp vợ chồng phải sinh nhiều con, duy trì mức sinh tự nhiên, là để đảm bảo khi về già, cha, mẹ già vẫn còn có ít nhất vài đứa con trưởng thành để làm chỗ dựa. Trong các xã hội phát triển hơn, khi mà hầu như những đứa con sinh ra đều có thể lớn lên, trưởng thành, các cặp vợ chồng không cần sinh nhiều con như trước nữa. Mặt khác, trong xã hội hiện đại, chi phí trực tiếp và chi phí gián tiếp nuôi con rất tốn kém. Do đó, các yếu tố này càng làm cho nhu cầu sinh nhiều con không cần thiết nữa, và chúng làm cho mức sinh cũng giảm xuống theo mức tử vong. Khi cả mức tử vong và mức sinh của dân số đều xuống thấp ở trong một xã hội, thì có thể coi xã hội đó đã đi qua thời kỳ quá độ dân số.

Thời kỳ quá độ dân số là thời kỳ các xã hội chuyển từ thời kỳ có mức sinh và mức chết đều cao sang thời kỳ có cả mức sinh và mức chết đều thấp. Thời kỳ quá độ dân số diễn ra khi các xã hội bước vào quá trình hiện đại hóa. Trong xã hội hiện đại, về cơ bản, hành vi sinh đẻ của con người là hành vi xã hội. Bởi vì, các cặp vợ chồng hay người phụ nữ hoàn toàn có thể lựa chọn số con mong muốn, cũng như thời điểm sinh con phù hợp với điều kiện sống của họ.

Bùng nổ dân số lần thứ hai trên Thế giới xảy ra ở các nước đang phát triển thuộc châu Á, Phi, Mỹ La Tinh ngay trong những năm sau chiến tranh Thế giới lần thứ II. Những năm đó ở các nước đang phát triển, mức tử vong cũng xuống thấp, nhờ hưởng lợi từ các thành tựu phát triển khoa học kỹ thuật và y học của nhân loại lan tỏa tới. Hầu hết các nước đang phát triển, trong thời kỳ sau chiến tranh Thế giới lần thứ II, đều có năng suất sản xuất lương thực, thực phẩm tăng lên, và thực hiện các chương trình tiêm chủng mở rộng. tương tự như ở các nước công nghiệp đi trước. Khi mức tử vong ở các nước đang phát triển đã xuống thấp thì các cặp vợ chồng ở đó cũng không có nhu cầu sinh nhiều con nữa, do đó mức sinh cũng bắt đầu giảm xuống ở các nước đang phát triển từ đầu những năm 60 của thế kỷ XX [3]. Mặt khác, nhằm thúc đẩy mức sinh xuống nhanh hơn so với việc giảm xuống một cách chậm chạp như ở các nước công nghiệp trước đó, những nước đang phát triển đã thực hiện các chương trình dân số-kế hoạch hóa gia đình (KHHGĐ). Mục tiêu chính của các chương trình KHHGĐ là đưa mức sinh giảm xuống bằng mức sinh thay thế, trung bình một phụ nữ chỉ có hai con. Và nhiều nước đang phát triển thời kỳ đó đã thực hiện thành công các chương trình 
KHHGĐ như Hàn Quốc, Thái Lan hay Singapore.

Từ việc mô tả quá trình biến đổi xã hội về dân số trong quá trình công nghiệp hóa, hiện đại hóa của cả hai nhóm các quốc gia phát triển và quốc gia đang phát triển, có thể thấy quá trình biến đổi xã hội về dân số của các quốc gia đều mang tính quy luật. Các quốc gia tiến hành công nghiệp hóa, hiện đại hóa, đều đi qua thời kỳ quá độ dân số. Kinh tế-xã hội càng phát triển thì mức sinh càng xuống thấp, người phụ nữ trong xã hội hiện đại ngày càng sinh ít con.

Từ quy luật về mối quan hệ giữa phát triển và mức sinh, và̀ từ thực tiễn biến động dân số của các quốc gia phát triển trên Thế giới trong những năm vừa qua, đã cho thấy một thực trạng mới của biến động mức sinh. Đó là, mức sinh ở các quốc gia phát triển cao, như Nhật Bản, Hàn Quốc, Singapore ở châu Á, hay Đức, Anh ở châu Âu, tiếp tục xuống thấp hơn cả mức sinh thay thế cần thiết. Số con trung bình của một phụ nữ ở các quốc gia này chỉ còn từ $1,1-1,4$ con. Nhật Bản và Đức đã trở thành những quốc gia có dân số rất già với tỷ trọng số người từ 65 tuổi trở lên chiếm hơn $21 \%$ dân số [4].

\section{Biến đổi mức sinh ở Việt Nam}

Với kết quả phân tích các số liệu về biến động dân số ở Việt Nam, có thể thấy rõ thời kỳ quá độ dân số ở Việt Nam bắt đầu từ khoảng cuối những năm 1950 cho đến năm 2005. Số con trung bình của một phụ nữ ở nước ta đã giảm từ khoảng 7,0 con, cuối những năm 1950, xuống còn 2,1 con năm 2005 .

Quá trình giảm mức sinh ở nước ta từ cuối những năm 1950 đến nay có thể chia ra làm ba giai đoạn. Giai đoạn thứ nhất bắt đầu từ cuối những năm 1950 đến 1988; Giai đoạn thứ hai từ 1989-2005; và giai đoạn thứ ba từ 2006 đến nay.

Trong giai đoạn thứ nhất, từ cuối những năm 1950 đến 1988, số con trung bình của một phụ nữ đã giảm từ khoảng 7,0 con xuống còn gần 4,0 con. Từ năm 1961, Việt Nam đã bắt đầu thực hiện chính sách dân số-KHHGĐ. Trong giai đoạn này, các giải pháp tuyên truyền-vận động được thực hiện là chủ yếu. Trong khoảng 30 năm, mức sinh ở nước ta đã giảm khá nhiều. Số con trung bình của một phụ nữ chỉ còn gần 4 con. Tuy nhiên, so với một số nước đang phát triển khác ở châu Á và khu vực Đông Nam Á như Hàn Quốc, Singapore hay Thái Lan, mức sinh như vậy ở nước ta vẫn còn khá cao, chưa giảm xuống mức sinh thay thế. Mức sinh còn khá cao như vậy là một yếu tố cản trở việc thực hiện các kế hoạch phát triển kinh tế-xã hội của đất nước khi đi vào thời kỳ đẩy mạnh quá trình công nghiệp hóa, hiện đại hóa.

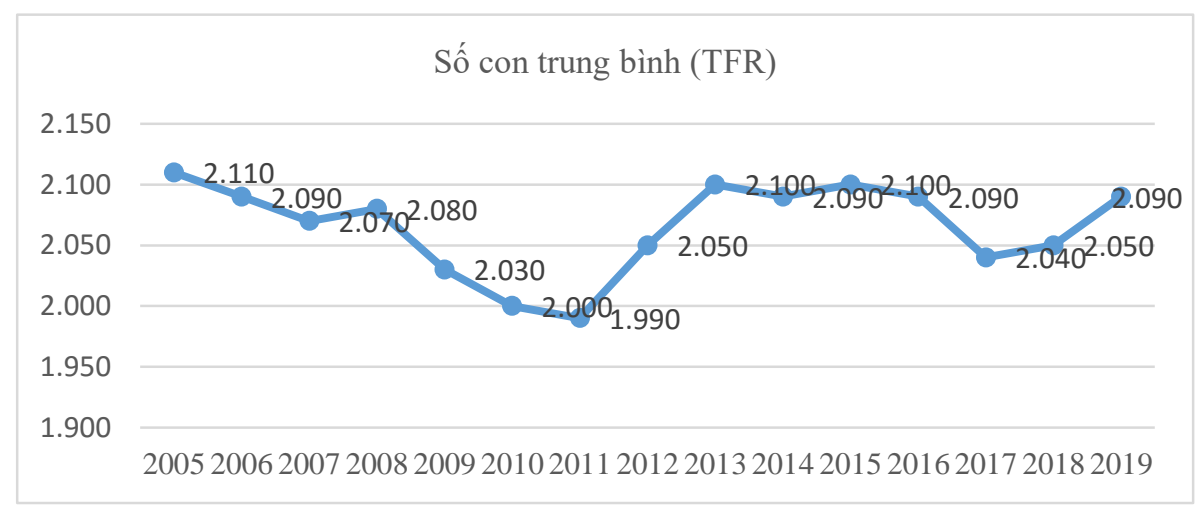

Biểu đồ 1. Biến đổi mức sinh ở Việt Nam, 2005-2019¹ .

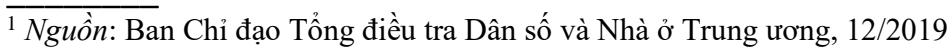


Trong giai đoạn thứ hai, từ năm 1989 đến 2005, với mục tiêu giảm mức sinh nhanh hơn và cố gắng sớm đạt mức sinh thay thế, bên cạnh giải pháp tuyên truyền-vận động được thực hiện mạnh mẽ hơn, một số giải pháp khác cũng được thực hiện một cách đồng bộ. Đó là, giải pháp về cung cấp dịch vụ KHHGĐ một cách thuận tiện nhất cho người dân. Các cặp vợ chồng hay người phụ nữ ở tất cả các địa phương, từ nông thôn đến thành thị đều có thể tiếp cận các dịch vụ cung cấp các biện pháp tránh thai an toàn với giá thấp hoặc miễn phí. Một giải pháp quan trọng tiếp theo là tổ chức bộ máy quản lý dân số-KHHGĐ. Bộ máy này lần đầu tiên đã được tổ chức một cách chặt chẽ từ trung ương xuống tới các thôn/bản/tổ dân phố. Tổ chức bộ máy như vậy đã hỗ trợ tích cực cho các hoạt động tuyên truyền-vận động thực hiện KHHGĐ tới tận từng hộ gia đình. Một giải pháp quan trọng nữa là thực hiện huy động toàn bộ hệ thống chính trị tham gia thực hiện chính sách dân số-KHHGĐ. Với các giải pháp đồng bộ được thực hiện một cách nghiêm túc, tích cực, Việt Nam đã sớm đạt được mức sinh thay thế vào năm 2005. Mục tiêu này đạt được sớm trước 10 năm so với yều cầu của Nghị quyết Trung ương 4 về công tác dân số-KHHGĐ năm 1993.
Trong giai đoạn thứ ba, từ năm 2006 đến nay, mục tiêu chính sách dân số của Chính phủ Việt nam là duy trì ổn định mức sinh thay thế. Kết quả Tổng điều tra dân số và nhà ở năm 2019 cho thấy, số con trung bình của một phụ nữ tương đối ổn định xấp xỉ mức 2,1 con trong 15 năm vừa qua (Biểu đồ 1 ). Như vậy, Việt Nam đã thành công trong việc thực hiện mục tiêu chính sách dân số trong giai đoạn này là giữ ổn định mức sinh thay thế.

\section{Mức sinh giảm và già hóa dân số}

So với các quốc gia khác trên Thế giới, mức sinh ở nước ta đã giảm xuống mức sinh thay thế tương đối nhanh trong một thời gian tương đối ngắn (1989-2005). Mức sinh giảm như vậy đã có tác động rõ rệt tới cấu trúc dân số. Mức sinh giảm đã có tác động trước hết tới việc làm giảm tỷ trọng trẻ em trong cấu trúc dân số. Tỷ trọng nhóm dân số trẻ em (0-14 tuổi) đã giảm rất nhanh trong vòng 20 năm (1989-2009). Tỷ trọng này đã giảm từ $39,2 \%$ năm 1989 , xuống còn $24,5 \%$ năm 2009. Trong mười năm vừa qua, tỷ trọng nhóm dân số trẻ em chỉ giảm nhẹ từ 24,5 xuống $24,3 \%$ [5], trong bối cảnh mức sinh ở nước ta được duy trì ở mức sinh thay thế.

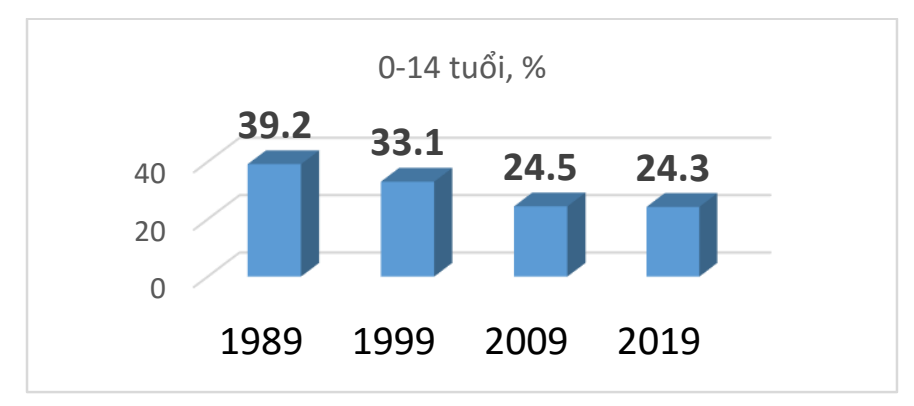

Biểu đồ 2. Tỷ trọng nhóm dân số trẻ em ở Việt nam, 1989-2019²

Trong giai đoạn 20 năm từ 1989-2009, biến đổi cấu trúc tuổi của dân số Việt nam có đặc điểm nổi bật là, tỷ trọng nhóm dân số trẻ em giảm nhanh trong khi tỷ trọng nhóm dân số người già (từ 65 tuổi trở lên) tăng lên không đáng kể (từ
4,7 lên 6,4\%). Do đó, tỷ trọng nhóm dân số trong độ tuổi lao động từ 15-64 (theo chuẩn quốc tế) đã tăng nhanh. Tỷ trọng nhóm dân số lao động đã tăng từ 56,1 lên 69,1\% (xem Biểu đồ 3). 


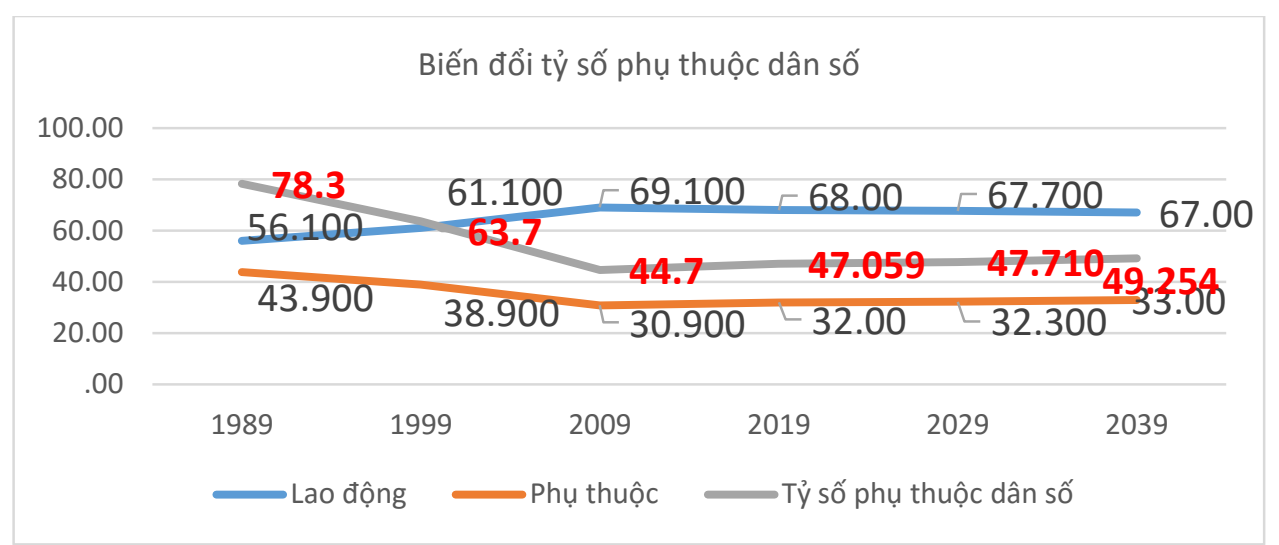

Biểu đồ 3. Tỷ số phụ thuộc dân số ở Việt nam, 1989-2039³.

Trong nghiên cứu kinh tế dân số, các nhà khoa học sử dụng khái niệm tỷ số phụ thuộc dân số. Tỷ số này được đo bằng tổng số trẻ em (0-14 tuổi) và người già (từ 65 tuổi trở lên trên 100 người trong độ tuổi lao động (15-64). Khi tỷ số phụ thuộc dân số nhỏ hơn 50, các nhà khoa học gọi đó là thời kỳ dân số "vàng" [6], khi đó số người trong độ tuổi lao động nhiều gấp đôi số người phụ thuộc (trẻ em và người già). Các số liệu trình bày trên Biểu đồ 3 (các số liệu năm 2029 và 2039 là dự báo) [7] cho thấy, thời kỳ dân số "vàng" ở nước ta bắt đầu khoảng năm 20062007 , và sẽ kéo dài đến khoảng năm 2040. Theo các số liệu Tổng điều tra dân số năm 2019, tỷ số phụ thuộc dân số ở Việt nam năm 2019 là 47,1 $(<50)$.

Mặc dù, đất nước đang ở trong thời kỳ có cơ cấu dân số vàng, nhưng cũng đã sớm bước vào quá trình già hóa dân số. Từ năm 2012 đến nay, nước ta đã bước vào quá trình già hóa dân số, với tỷ lệ số người từ $65+$ trở lên chiếm $7 \%$ quy mô dân số. Kêt quả Tổng điều tra dân số năm 2019 cho biết, tỷ lệ số người già hiện nay $(65+)$ chiếm hơn 7,7\%; Chỉ số già hóa dân số năm 2019 là 48,8\%, tăng 13,3 điểm phần trăm so với năm 2009 và tăng hơn hai lần so với năm 1999; chỉ số già hóa dân số có xu hướng tiếp tục tăng nhanh hơn trong 10 năm sắp tới [5]. Việt Nam đang ở trong thời kỳ quá độ chuyển từ cơ cấu dân số trẻ sang cơ cấu dân số già. Thời kỳ quá độ này được coi là thời kỳ già hóa dân số.

Già hóa dân số là quá trình biến đổi cấu trúc dân số mang tính quy luật đối với tất cả các quốc gia khi bước vào quá trình công nghiệp hóa, hiện đại hóa, một quá trình biến đổi xã hội từ xã hội nông nghiệp truyền thống lên xã hội công nghiệp hiện đại. Tuy nhiên, già hóa dân số đang đặt ra nhiều thách thức đối với phát triển kinh tế-xã hội của Việt Nam, bởi vì quá trình già hóa dân số sẽ diễn ra tương đối ngắn. Theo dự báo (Biểu đồ 3 ), quá trình già hóa dân số ở Việt Nam chỉ kéo dài khoảng hơn 30 năm, kết thúc trước năm 2040. So với các quốc gia khác thì Việt Nam nằm trong số các quốc gia có thời kỳ già hóa dân số ngắn nhất. Những thách thức đang đặt ra trở nên ngày càng lớn khi đất nước chưa hoàn thành mục tiêu kết thúc quá trình công nghiệp hóa. Các hệ thống về $\mathrm{y}$ tế và an sinh xã hội có thể không kịp chuyển đổi cấu trúc để thích ứng với một xã hội có cơ cấu dân số già.

Trong giai đoạn mười năm vừa qua (20092019), mặc dù mức sinh của dân số Việt Nam được duy trì và giữ tương đổi ổn định ở mức sinh thay thế nhưng chỉ số già hóa dân số vẫn tiếp tục tăng lên và có xu hướng tiếp tục tăng nhanh hơn trong giai đoạn từ nay đến năm 2030 . Nhịp độ biến đổi mức sinh có mối quan hệ chặt chẽ với quá trình già hóa dân số. Nếu mức sinh xuống 
thấp hơn và biến đổi nhanh hơn, quá trình già hóa dân số sẽ diễn ra ngắn hơn. Những thách thức đang đặt ra như nêu trên đòi hỏi các giải pháp mới của chính sách dân số cần có tác động làm chậm lại quá trình giảm mức sinh, qua đó có thể kéo dài hơn quá trình già hóa dân số.

\section{Chính sách dân số giai đoạn từ nay đến 2030}

Những biến đổi xã hội về cấu trúc dân số như mô tả ở trên đã đặt ra yêu cầu về đổi mới chính sách dân số trong giai đoạn mới từ nay đến 2030. Tháng 10 năm 2017, Ban Chấp hành Trung ương Đảng khóa XII đã ra Nghị quyết 21$\mathrm{NQ} / \mathrm{TW}$ về công tác dân số trong tình hình mới. Nghị quyết 21 đã yêu cầu "Tập trung moi nỗ lực chuyển trọng tâm chính sách dân sồ tù kế hoạch hóa gia đình sang thưc hiện và đạt đurợc các muc tiêu toàn diện cả về quy mô, co cấu, phân bố, đặc biệt là chất luợng dân số và được đặt trong mối quan hệ hũu cơ với các yếu tố kinh tế, xã họii, quốc phòng, an ninh".

Tháng 11 năm 2019, Thủ tướng Chính phủ đã có Quyết định 1679/QĐ-TTg Phê duyệt Chiến lược Dân số Việt Nam đến năm 2030. Chiến lược có mục tiêu tồng quát: "Duy trì vũng chắc mức sinh thay thế; đưa tỉ số giới tính khi sinh về mức cân bằng tư nhiên; tận dụng hiệu quả cơ cấu dân số vàng; thich ứng với già hóa dân số; phân bố dân số hợ lý và nâng cao chất luợng dân số, góp phần phát triển đẩt nước nhanh, bền vũng".

Một vấn đề đặt ra liên quan tới việc thực thi chính sách dân số hiện nay là thực trạng biến đổi mức sinh không đồng đều giữa các vùng và các tỉnh, thành phố trong cả nước. Có 21 tỉnh, thành phố có mức sinh thấp hơn mức sinh thay thế; 33 tỉnh, thành phố có mức sinh cao hơn mức sinh thay thế; và 9 tỉnh có mức sinh ngang bằng với mức sinh thay thế.

Theo Quyết định 588 ngày 28 tháng 4 năm 2020 của Thủ tướng Chính phủ, nhằm duy trì vững chắc mức sinh thay thế trong cả nước, phấn đấu tăng mức sinh ở những địa phương đang có mức sinh thấp, giảm mức sinh ở những địa phương đang có mức sinh cao. Cụ thể là, i) Tăng
10\% tổng tỷ suất sinh ở các tỉnh, thành phố có mưc sinh thấp; ii) Giảm 10\% tổng tỷ suất sinh ơ các tỉnh, thành phố có múc sinh cao; và iii) Duy trì kết quả ở nhũng tỉnh, thành phố đã đạt mức sinh thay thế.

Thực tiễn biến động dân số của nhiều quốc gia phát triển trên Thế giới như Nhật Bản, hay các nước ở châu Âu và Bắc Mỹ, cho thấy các quốc gia này đều đã đi qua thời kỳ quá độ dân số mà không cần thực hiện chính sách dân sốKHHGĐ.

Bảng 1. Số con trung bình và tỷ trọng dân số trẻ em ở một số quốc gia, 2018

\begin{tabular}{|l|c|c|}
\hline Quốc gia & $\begin{array}{c}\text { Số con trung } \\
\text { bình } \\
\text { TFR }\end{array}$ & $\begin{array}{c}\text { Tỷ trọng trẻ } \\
\text { em } \\
(0-14)\end{array}$ \\
\hline Nhật Bản & 1,4 & $12 \%$ \\
\hline Hàn Quốc & 1,1 & $13 \%$ \\
\hline Singapore & 1,2 & $15 \%$ \\
\hline Trung Quốc & 1,8 & $17 \%$ \\
\hline Thái Lan & 1,5 & $17 \%$ \\
\hline Việt Nam (2019) & 2,1 & $24,3 \%$ \\
\hline
\end{tabular}

Từ quy luật về mối quan hệ giữa phát triển và mức sinh, và từ thực tiê̂n biến động dân số của các quốc gia phát triển trên Thế giới trong những năm vừa qua, đã cho thấy một thực trạng mới của biến động mức sinh. Đó là, mức sinh ở các quốc gia phát triển cao, như Nhật Bản, Hàn Quốc, Singapore ở châu Á, hay Đức, Anh ở châu Âu, tiếp tục xuống thấp hơn cả mức sinh thay thế cần thiết.

Khi mức sinh xuống thấp dưới mức sinh thay thế, tỷ trọng trẻ em sẽ giảm xuống ở mức dưới 20\% (Bảng 1), trong khi đó, tỷ trọng người già luôn luôn tăng lên với tốc độ ngày càng nhanh do yếu tố tuổi thọ được nâng lên. Các yếu tố này sẽ đưa tỷ số phụ thuộc dân số trở lại mức trên 50 . Tỷ số này không thể một lần nữa xuống thấp dưới 50 vì mức sinh, theo quy luật, không thể tăng cao trở lại như trước kia. Thực tiễn biến động dân số của nhiều quốc gia phát triển cũng đã cho thấy quy luật, một khi đề cho mức sinh giảm xuống quá thấp sẽ không thể đưa mức sinh tăng lên trở lại. Do đó, mục tiêu tăng $10 \%$ tổng 
tỷ suất sinh của 21 tỉnh, thành phố có mức sinh thấp là khó khả thi.

Nếu mục tiêu tăng $10 \%$ tổng tỷ suất sinh của 21 tỉnh, thành phố có mức sinh thấp là khó khả thi thì mục tiêu giảm $10 \%$ tổng tỷ suất sinh của 33 tỉnh, thành phố có mức sinh cao lại hoàn toàn khả thi. Bởi vì, theo quy luật, trong bối cảnh nước ta tiếp tục đẩy mạnh công nghiệp hóa, hiện đại hóa, mức sinh ở 33 địa phương này vẫn tiếp tục nằm trong xu hướng giảm ngay cả khi không có chính sách KHHGĐ. Như đề cập ở trên, chính sách KHHGĐ có tác động làm cho mức sinh giảm nhanh hơn so với việc giảm xuống một cách tự nhiên theo tiến trình phát triển kinh tế-xã hội.

Bảng 2. Tỷ trọng người già ở một số quốc gia, 20182050

\begin{tabular}{|l|l|l|}
\hline \multirow{2}{*}{ Quốc gia } & \multicolumn{2}{|l|}{ Tỷ trọng người già (65+) } \\
\cline { 2 - 3 } & 2018 & 2050 (Dự báo) \\
\hline Nhật Bản & $28 \%$ & $36 \%$ \\
\hline Hàn Quốc & $14 \%$ & $35 \%$ \\
\hline Singapore & $13 \%$ & $34 \%$ \\
\hline Trung Quốc & $11 \%$ & $26 \%$ \\
\hline Thái Lan & $12 \%$ & $29 \%$ \\
\hline Việt Nam (2019) & $7,7 \%$ & $22 \%$ \\
\hline
\end{tabular}

Nguồn: PRB, 2018. World Population Datasheet. 2018. www.prb.org

Nếu như vậy, nước ta có thể không thực hiện được mục tiêeu chung của Chính sách dân số từ nay đến năm 2030 là "Duy trì vũng chắc mức sinh thay thế trên toàn quốc".

\section{Kết luận}

Từ mối quan tâm về tăng trưởng kinh tế có thể thấy, tiềm năng tăng trưởng của một nền kinh tế phụ thuộc vào mức tăng năng suất lao động và tỷ lệ tăng trưởng nguồn nhân lực [8]. Khuynh hướng giảm dần tỷ lệ tăng trưởng nguồn nhân lực ở Việt nam đã bắt đầu từ cuối thập niên đầu của thế kỷ XXI [9]. Việc thực hiện mục tiêu về duy trì vững chắc mức sinh thay thế trên toàn quốc sẽ góp phần làm chậm lại tốc độ giảm tỷ lệ tăng trưởng nguồn nhân lực trong cả nước.

Từ góc độ về di cư và dịch chuyển lao động trong nền kinh tế thị trường, nguồn nhân lực sẽ từ các địa phương có nhiều lao động dịch chuyển dễ dàng tới các địa phương khác đang thiếu lao động. Trên phạm vi toàn quốc, nguồn nhân lực ở 33 tỉnh, phố có mức sinh cao hơn sẽ có thể giúp cân đối với nguồn nhân lực ở 21 tỉnh, thành phố có mức sinh thấp hơn. Do đó, việc đặt ra mục tiêu giảm $10 \%$ tổng tỷ suất sinh của 33 tỉnh, thành phố là không phù hợp trong bối cảnh phát triển kinh tế-xã hội ở nước ta hiện nay.

Trong giai đoạn từ nay đến 2030, các mục tiêu và giải pháp của chính sách dân số cần được thực hiện thống nhất trong phạm vi toàn quốc. "Việc rà soát, đề xuất sửa đổi các quy định không còn phù hợp với muc tiêu duy trì vũng chắc mức sinh thay thế, đặc biệt là các quy định xử lý vi phạm chính sách dân số hiện hành" [10] cần được thực hiện đồng bộ ở tất cả 63 tỉnh, thành phố trong cả nước.

Các mục tiêu và giải pháp của chính sách dân số ở nước ta trong giai đoạn từ nay đến năm 2030 đã được chuyển đổi một cách cơ bản. Việc thực hiện thành công mục tiêu chung của chính sách dân số có ý nghĩa đặc biệt quan trọng tới phát triển mọi mặt kinh tế, xã hội, quốc phòng, an ninh của đất nước.

\section{Tài liệu tham khảo}

[1] General Statistics Office and United Nations Population Fund, Fertility in Vietnam: Differences, Trends and Impact Factors (in Vietnamese), Vietnam News Agency Publishing House, Hanoi, 2016.

[2] Central Committee of the Communist Party of Vietnam, Resolution No. 21-NQ/TW on population work in the new stage (in Vietnamese), Hanoi, 2017..

[3] R. Stark, Sociology, Seventh Ed., University of Washington, Wadsworth Publishing Company, 1997.

[4] Population Reference Bureau (PRB), World Population Datasheet 2018. https://www.prb.org/2018- world-population-data- 
sheet-with-focus-on-changing-age-structures/ (accessed 31 May, 2019).

[5] Central Population and Housing Census Steering Committee, Population and housing census results at 0:00 on April 1, 2019 (in Vietnamese), Statistical Publishing House, December 2019.

[6] United Nations Population Fund, Taking advantage of the golden population opportunity in Vietnam: Opportunities, challenges and policy implications (in Vietnamese), Hanoi, December 2010.

[7] General Statistics Office - United Nations Population Fund, Population projection for Vietnam 2014-2049, 2016.
[8] R. Sharma, The Rise and Fall of Nations: Forces of Change in a Post-Crisis World (translated) (in Vietnamese), Phuong Nam Book Company Limited and The Gioi Publisher, 2018.

[9] B.P. Dinh, H.V. Hung, Golden population structure, aging population and challenges for development (in Vietnamese), Journal of Political Theory, 8/2019.

[10] Prime Minister, Decision 588/QD-TTg on Approval of "Program to adjust fertility rates to suit regions and subjects by 2030" (in Vietnamese), Hanoi, 28 April, 2020. 